East African Medical Journal Vol. 85 No. 7 July 2008

FERTILITY RATE OF EPILEPTIC WOMEN AT KENYATTA NATIONAL HOSPITAL

J.G. Kariuki, MBChB, Senior House Officer, M.D. Joshi, MBChB, MMed, MPH, FACC, Senior Lecturer, A.M. Adam, MBChB, FRCP (Ed), Associate Professor, T.O.O. Kwasa, MBChB, MMed, Senior Lecturer, Department of Clinical Medicine and Therapeutics and M. Machoki, MBChB, MMed, Senior Lecturer, Department of Obstetric and Gynaecology, College of Health Sciences, University of Nairobi, P.O. Box 19676-00202, Nairobi, Kenya

Request for reprints to: Dr. J.G. Kariuki, Department of Clinical Medicine and Therapeutics, College of Health Sciences, University of Nairobi, P.O. Box 19676-00202, Nairobi, Kenya

\title{
FERTILITY RATE OF EPILEPTIC WOMEN AT KENYATTA NATIONAL HOSPITAL
}

\author{
J.G. KARIUKI, M.D. JOSHI, A.M. ADAM, T.O.O. KWASA and M. MACHOKI
}

\begin{abstract}
Background: Reproductive health issues of women with epilepsy (WWE) are complex and multifaceted, and both epilepsy and antiepileptic drug (AEDs) use may alter fertility and pregnancy outcomes in these women.

Objective: To determine the fertility rate of women with epilepsy at Kenyatta National Hospital (KNH).

Design: Cross-sectional study.

Setting: Neurology clinic, KNH, Nairobi, Kenya, between October 2006 and March 2007.

Subjects: A total of 191 women with epilepsy (aged 15-49 years) who had been epileptic for at least one year were interviewed regarding their pregnancy and birth histories, and the information validated with medical records where available.

Results: The general fertility rate (GFR) for reproductive-aged epileptic women for the three-year period (2003-2006) preceding the study was 46 livebirths per 1000 women-years (95\% CI 35.1363.59).

Conclusion: Fertility rate in epileptic women is decreased by two thirds (compared to that of general population of women in Kenya). Reasons for this are probably miltifactorial.
\end{abstract}

\section{INTRODUCTION}

Fertility, in demographic terms, is defined as live births only. Women with epilepsy (WWE) have fewer children than women in general with a fertility rate reported to be $25 \%$ to $67 \%$ lower than average $(1,2)$. While personal choice and / or societal pressure may play some role in this disparity, research has indicted that women with epilepsy have a higher incidence of menstrual irregularities, polycystic ovarian disease and reproductive endocrine disorders. One third or more of menstrual cycles in women with generalised seizures are anovulatory $(3,4)$. A higher infertility rate has been reported in partial epilepsy than in idiopathic generalised epilepsies (5).
Unfortunately no study has been done locally to substantiate above findings. The primary objective of this study was to determine the GFR of WWE for the three-year period (2003-2006) preceding the study and to compare this rate with that of women in general as documented in the Kenya Demographic and Health Survey (KDHS) 2003 (6).

\section{MATERIALS AND METHODS}

This was a hospital-based cross-sectional study, done between October 2006 and March 2007, at the neurology clinic, Kenyatta National Hospital.

A minimum sample size of 185 epileptic women of reproductive age was required. All epileptic 
women aged 15 to 49 years who had epilepsy for at least one year, and who provided written and informed consent were included into the study. We excluded those who denied consent and those of whom history was unavailable.

Recruited women were interviewed regarding their pregnancy and birth histories, and this information validated with medical records where available. Data were analysed using the SPSS 12.0 software and descriptive statistics were done.

Approval to carry out this study was obtained from the Department of Clinical Medicine and Therapeutics (University of Nairobi) on 31st July 2006, and from the Ethics and Research Committee of Kenyatta National Hospital on 19th October 2006.

\section{RESULTS}

A total of 224 patients were screened over a fivemonth period. One hundred and ninety one were recruited, 31 were not eligible for various reasons (six were aged less than 15 years, 14 were aged more than 49 years, and 11 had duration of epilepsy of less than one year), and two were excluded (one denied consent, and one had undergone hysterectomy in the year 2000).

Social-demographic characteristics: Majority (70\%) of the patients were at peak childbearing age (20-39 years). The remaining 30\% were aged $15-19$ years $(17.5 \%)$ and $40-49$ years (12.5\%). The median age of our patients was 25 years, with a mean of $27.5 \pm$ 8.8 (95\% CI 26.1-28.7). Majority of patients (81.2\%) resided in Nairobi and Central province, while the rest in five provinces, and none in north eastern province.

Analysis of marital status showed that majority (136 patients, 71.2\%) had never married. The rest were either currently married (48 women, $25.1 \%$ ) or formerly married (five divorced, one separated, and one widowed). For those currently married ( $\mathrm{n}=$ 48), the median duration of marriage was ten years (range 1-32 years), with a mean duration of $11.7 \pm$ 8.8 (95\% CI 9.16-14.16).

Majority of patients were fairly well educated with $60.7 \%$ having attained secondary and above level of education. Only five (2.6\%) patients had never received any formal education. A slight majority (112 patients, 58.7\%) were unemployed, of whom $37(33 \%)$ were students.
The rest were either self employed or formally employed (21\% and $20.4 \%$ respectively). Majority of patients were from three tribes: Kikuyu $(70.2 \%)$, Kamba (12.6\%), and Luo (6.2\%).

Table 1 shows the age of patients $(\mathrm{n}=175)$ at menarche (in years), cycle length, and duration of menstrual flow in days. The median and mean age at menarche was 14 years and $14.27 \pm 1.54$ (95\% CI 13.96-14.48) respectively. The median length of the menstrual cycles was 28 days, with a mean length of $27.39 \pm 3.01$ (95\% CI 25.89-28.89). The median duration of menstrual flow was three days. Women with regular menstrual cycles comprised $85.7 \%$, while the rest had irregular menstrual cycles.

Table 2 shows the type and frequency of contraceptive use by WWE. A total 163 (85.3\%) patients were not using any contraceptive method. Of the $28(14.7 \%)$ who were on contraception, the median and mean duration of contraceptive use was 5.5 years (range $1-10$ years) and $4.83 \pm 2.73$ years (95\% CI 3.48- 6.19) respectively. Two patients had undergone BTL six years prior to the study and were included in fertility calculation. The reason for their inclusion was because BTL, like any other family planning method, does not offer $100 \%$ protection from the risk of conception and giving birth.

Epilepsy and antiepileptic drug (AED) use: The median duration of epilepsy was seven years (range 1-42 years), interquartile range of 13 years, and a mean duration of $11.12 \pm 9.12$ years. A total of 112 patients (59.69\%) had generalised seizures while the rest had partial seizures. Regarding AED use, 120 (62.8\%) patients were on single therapy, $61(31.9 \%)$ on dual therapy and the rest on either triple therapy (six patients, 3.1\%), quadri-therapy (two patients, $1.1 \%$ ), or no therapy at all (two patients, $1.1 \%$ ). Carbamazepine was the most commonly used drug, singly or in combination.

Table 3 summarises the distribution of livebirths (as at June 2006 and in the three years preceding the study) as per current women age-groups. As at June 2006, only $40.3 \%$ of all 191 WWE had ever given birth, to a total of 173 livebirths. Ninety four of the livebirths had been born outside epilepsy illness while 79 within epilepsy illness. Of the 79 livebirths, 34 and 25 were born in five and three years prior to the survey respectively. Only eight of the 79 livebirths were born at $\mathrm{KNH}$ (study institution). The places of delivery of the total 173 livebirths included: 
15 at KNH, 132 at other health centres all over Kenya, and 25 at home. A total of fourteen livebirths had died by the time of survey.

Majority of the livebirths $(151,87.3 \%)$ were born via spontaneous vaginal delivery, 18 (10.4\%) via Caeserian section, and the rest four $(2.3 \%)$ by breech delivery. The reasons for Caesarean sections were: foetal distress $(27.3 \%)$, epilepsy $(18.2 \%)$, malpresentation $(9.1 \%)$, and others $(45.4 \%)$.
General fertility rate (GFR): The 191 WWE of childbearing age had 25 livebirths in the three years preceding the study (2003 to 2006). The GFR of reproductive age (15-49 years) WWE for the threeyear period was 45.87 livebirths per 1000 womenyears (95\% CI 35.13/1000-63.59 / 1000). The GFR for epileptic women aged 15-44 years was 50.3 livebirths per 1000 women-years. Only four women (2.1\%) were pregnant at the time of survey.

Table 1

Age at menarche in years, cycle length and duration of menstrual flow in days

\begin{tabular}{lccc}
\hline & Mean & Median & Range \\
\hline Age at menarche in years & $14.3 \pm 1.5$ & 14 & $11-19$ \\
Length of cycle in days & $27.4 \pm 3.0$ & 28 & $18-30$ \\
Duration of flow in days & $3.63 \pm 1.14$ & 3 & $1-7$ \\
\hline
\end{tabular}

Table 2

Type and frequency of contraceptive use by study patients

\begin{tabular}{lcc}
\hline Contraceptive method & No. of users & $(\%)$ \\
\hline Injectables & 11 & 39.3 \\
IUCD & 4 & 14.3 \\
Condoms & 2 & 7.1 \\
BTL & 2 & 7.1 \\
\hline Total & 28 & 100 \\
\hline
\end{tabular}

Table 3

Distribution of livebirths as per women's age group

\begin{tabular}{lccc}
\hline $\begin{array}{l}\text { Age-group (patients) } \\
\text { (years) }\end{array}$ & No. of patients & Total livebirths (by June 2006) & $\begin{array}{c}\text { Livebirths in three } \\
\text { presurvey years }\end{array}$ \\
\hline $15-19$ & 34 & 0 & 0 \\
$20-24$ & 59 & 15 & 10 \\
$25-29$ & 32 & 25 & 8 \\
$30-34$ & 29 & 36 & 6 \\
$35-39$ & 13 & 25 & 1 \\
$40-44$ & 8 & 15 & 0 \\
$45-49$ & 16 & 57 & 0 \\
\hline Total & 191 & 173 & 25 \\
\hline
\end{tabular}




\section{DISCUSSION}

Our sample was representative of the population of WWE at KNH as majority (85.3\%) of all screened were recruited. In addition, the social-demographic characteristics of study patients were similar to that reported by Kwasa et al (7) who carried out a study on bone metabolism in WWE of reproductive age in the same institution. There was no overlap in study period between this study and ours. Comparative national data on fertility level of WWE lacked, hence it is not clear whether our study sample represented WWE in Kenya.

General fertility rate (GFR) refers to the number of livebirths per 1,000 person-years lived by the population of reproductive-aged women. It is one of the current measures of fertility, the others being: crude birth rate (CBR), age specific fertility rate (ASFR), and total fertility rate (TER). The GFR of WWE stood at 45.87 livebirths per 1,000 womenyears lived. This is two thirds of that reported in the KDHS 2003 (6). This reduction was further supported by the low current pregnancy rate $(2.1 \%)$ for study subjects, as compared to a rate of $7.8 \%$ in the general population (6). The proportion of all women who are currently pregnant (in a population) is an indicator of future fertility in that population.

We utilised the KDHS 2003 GFR, for the period ending 2003, as representative of the general population of Kenyan women (morbidity status not stated), and compared it to that of our study of WWE at $\mathrm{KNH}$; as this is based available population data. We however acknowledge the different study periods of this data, but feel that this does not compromise the comparison, as a general drop in GFR in the general population would be expected to similarly affect WWE.

The reasons for the disparity between fertility in epileptic women and that in general are not obviously clear, and a study specifically to evaluate the reasons is recommended. Our study was not designed nor powered to address this question. Literature reports that WWE have fewer children than women in general, with a fertility rate of $25 \%$ to $67 \%$ lower than average (12). Suggested reasons include: personal choice, societal pressure, fear of malformations and in transmitting epilepsy to their offsprings, higher incidence of menstrual irregularities, and reproductive endocrine disorders secondary to epilepsy and AEDs use.
Seventy one per cent of all our study patients reported never having been married. Marriage is a principal indicator of women's exposure to the risk of pregnancy (6). The high proportion of never married women could partly explain the reduced fertility rate. Among the never married WWE, only one (8.4\%) had ever given birth in their lifetime, compared to $94.6 \%$ of the married / ever married women. This difference was statistically significant with a p-value $<0.05$. In the KDHS 2003 (6) the proportion of never married, currently married, and formerly married women was 30,60 and $10 \%$ respectively.

The practice of family planning is another important proximate determinant of fertility. In contemporary societies, fertility has become largely determined by behaviour and by choice, through voluntary regulation. In this study only $14.7 \%$ of the study patients were practising contraception at the time of survey, as compared to $28.4 \%$ in KDHS 2003. This suggests that study epileptic women were not as sexually active as women surveyed in KDHS 2003.

In the absence of contraception, the chance of becoming pregnant is related to the frequency of sexual intercourse (6). In our study we did not specifically inquire about sexual activity in WWE. However women who report using no contraceptive method are less likely to have had a recent sexual encounter. This is not surprising as many of those in KDHS 2003 who were not on contraceptive method reported not to have had recent sexual encounter (6).

Majority of our patients $(81.15 \%)$ resided in Nairobi and Central province. Women from these two provinces have the lowest fertility level, as per the KDHS 2003, compared to the other six provinces. None of our patients resided in North Eastern province which is reported to have women with highest fertility rate in Kenya (6).

Majority of the study patients were fairly well educated, with $60.7 \%$ having attained at least a secondary level education. Only $29.4 \%$ of the women in KDHS 2003 had attained similar level of education. Education of women is strongly associated with lower fertility, and as per KDHS (6), fertility decreased by $52.2 \%$ for women without education to those with secondary education. It is possible that the higher educational attainment in study epileptic women may have contributed to the lower fertility, but this cannot be stated conclusively, since the study was not designed to answer such a question. 
It is not clear what role social economic status of study subjects played in influencing fertility. According to KDHS (6) fertility is very closely associated with wealth, with disparity in fertility between the poorest and the richest women being in the order of almost five children per woman. Although we did not specifically inquire on level of wealth, it is important to note a slight majority $(58.7 \%)$ of WWE in our study were unemployed. None of students (who comprised $33 \%$ of unemployed WWE) had ever given birth. Fifty four point two per cent of unemployed WWE and $45.8 \%$ of the employed had ever given birth in last three years preceding the study. This difference was not statistically significant.

Literature reports that both seizures and AEDs can disturb reproductive health through menstrual irregularities, anovulatory cycles, polycystic ovarian-like syndrome, and sexual dysfunction. In our study only $14.3 \%$ of WWE reported menstrual irregularities. Although possibility exists that some of WWE had anovulatory cycles, it is not possible to state what percentage this constituted. Literature reports about a third of menstrual cycles in women with generalised seizures are anovulatory $(3,4)$.

It is not clear whether or not seizure type contributed to the low fertility in WWE. Literature reports that partial epilepsy is associated with lower fertility compared to generalised epilepsies (5). In our study $40.3 \%$ of the patients had partial seizures while the rest suffered generalised seizures. Only $12.3 \%$ and $12.7 \%$ of those with partial and generalised seizures (respectively) had given birth in the last three years preceding the study. This difference (on chi-square testing) was not statistically significant.

No local study had previously been carried out to examine fertility level in epileptic patients, and thus ours is the first study of its kind in East Africa. A crosssectional survey done in Cameroon by Kamgno et al (8) in 2001 reported that epileptic women had lower fertility compared to controls (average children per woman was 1.63 compared to 2.3 in controls). Most studies carried out in western countries reported low fertility level in epileptic women. Dansky et al (9) in 1980 reported that fertility in epileptic women was reduced by $31 \%$, Wallace et al (10) in a population based study in UK reported a $24.8 \%$ fertility reduction, and Olafsson et al (11) in 1998 in a retrospective cohort study in Iceland reported no difference in fertility rate between patients and controls. A study in Finland by Javala and Sillanpaa(12) found out that persons with epilepsy were less likely to marry and to have offsprings.

One limitation of a study of this nature is recall bias. To minimise this, medical records (where available) were used to validate information. The effect of this bias on our primary aim was insignificant or absent, since none of the women interviewed had forgotten the number of children they had given birth to. In addition the tool used for data collection was similar to that used by the KDHS 2003 (source of comparative data). The sample size was inadequate for more refined measures of current fertility such as age specific fertility rate, and total fertility rate. Such rates require over seven times our current sample size. Lastly our results may or may not be generalisable to the rest of population of epileptic women in Kenya since no comparative data exists.

In conclusion, fertility rate of WWE is reduced by two thirds and the reasons for this are probably multifactorial. A study to investigate this disparity is highly recommended.

\section{ACKNOWLEDGEMENTS}

This study formed part of a Masters Thesis of the University of Nairobi by the first author. The authors are grateful and extend their sincere thanks to the heads of Kenyatta National Hospital and the Department of Clinical Medicine and Therapeutics (University of Nairobi) for allowing this study to be undertaken.

\section{REFERENCES}

1. Yerby, M. Treatment of epilepsy during pregnancy. second edition. Williams and Wilkins. 1996; 785-798.

2. ACOG Educational Bulletin. Seizure disorders in pregnancy. Amer. Coll. Obstet. Gyn. 1996; 231.

3. Murialdo, G. Menstrual cycle and ovary alterations in women with epilepsy on antiepileptic therapy. S. Endocrinol. Invest. 1997; 20: 519.

4. Kumar, P. Epilepsy in women. Clin. Med. 5th edn. W.B. Saunders. 2000; 20: 1179.

5. Caughey, A.B. Seizure disorders in pregnancy. E. Medicine. Last Updated: August, 2005.

6. Opiyo, C. Fertility levels, trends, and differentials. Kenya Demogr. Hlth. Surv. 2003; 4: 51-62.

7. Kwasa, J.K., Kwasa, O., Amayo, A., et al. Bone metabolism in ambulatory premenopausal women 
using antiepileptic drugs, attending the neurology clinic at Kenyatta National Hospital. MMed Dissertation, University of Nairobi, 2007.

8. Kamgno, J., Pion, S.D.S. and Boussinesq, M. Demographic impact of epilepsy in Africa: Results of a 10-year cohort study in a rural area of Cameroon. Epilepsia. 2003; 44: 956-963.

9. Dansky, L.V., Andermann, E. and Andermann, F. Marriage and fertility in epileptic patients. Epilepsia. 1980; 21: 261-271.
10. Wallace, H., Shorvon, S. and Tallis, R. Age-specific incidence and prevalence rates of treated epilepsy in an unselected population of 2,052,922 and age-specific fertility rates of women with epilepsy. Lancet. 1998; 352: 1970-1973.

11. Olafsson, E., Hauser, W.A. and Gudmundsson, G. Fertility in patients with epilepsy. Neurology. 1998; 51: 71-73.

12. Javala, M. and Sillanpaa, M. Reproductive activity and offspring health of young adults with childhoodonset epilepsy: A control led study. Epilepsia. 1997; 38: 532-540. 